\title{
Numerical Analysis of Nanofluids in Differentially Heated Enclosure Undergoing Orthogonal Rotation
}

\author{
H. Saleh ${ }^{1}$ and I. Hashim ${ }^{1,2,3}$ \\ ${ }^{1}$ Centre for Modelling \& Data Analysis, School of Mathematical Sciences, Universiti Kebangsaan Malaysia, \\ UKM 43600 Bangi, Selangor, Malaysia \\ ${ }^{2}$ Solar Energy Research Institute, Universiti Kebangsaan Malaysia, UKM 43600 Bangi, Selangor, Malaysia \\ ${ }^{3}$ Department of Mathematics, Faculty of Science, King Abdulaziz University, P. O. Box 80257, Jeddah 21589, Saudi Arabia
}

Correspondence should be addressed to H. Saleh; dr.habibissaleh@gmail.com

Received 29 October 2013; Accepted 21 February 2014; Published 6 April 2014

Academic Editor: Yao-Zhong Zhang

Copyright ( $2014 \mathrm{H}$. Saleh and I. Hashim. This is an open access article distributed under the Creative Commons Attribution License, which permits unrestricted use, distribution, and reproduction in any medium, provided the original work is properly cited.

\begin{abstract}
Natural convection heat transfer in a rotating, differentially heated enclosure is studied numerically in this paper. The rotating enclosure is filled with water- $\mathrm{Ag}$, water- $\mathrm{Cu}$, water- $\mathrm{Al}_{2} \mathrm{O}_{3}$, or water- $\mathrm{TiO}_{2}$ nanofluids. The governing equations are in velocity, pressure, and temperature formulation and solved using the staggered grid arrangement together with MAC method. The governing parameters considered are the solid volume fraction, $0.0 \leq \phi \leq 0.05$, and the rotational speeds, $3.5 \leq \Omega \leq 17.5 \mathrm{rpm}$, and the centrifugal force is smaller than the Coriolis force and both forces were kept below the buoyancy force. It is found that the angular locations of the local maximums heat transfer were sensitive to rotational speeds and nanoparticles concentration. The global quantity of heat transfer rate increases about $1.5 \%, 1.1 \%, 0.8 \%$, and $0.6 \%$ by increasing $1 \% \phi$ of the nanoparticles $\mathrm{Ag}, \mathrm{Cu}, \mathrm{Al}_{2} \mathrm{O}_{3}$, and $\mathrm{TiO}_{2}$, respectively, for the considered rotational speeds.
\end{abstract}

\section{Introduction}

The fluid flow and heat transfer characteristics of a rotating enclosure were treated in detail according to its functional and practical importance in the design of guided missiles and a rotating electrical machine. Consistently too high temperature occurring in the rotating machine will reduce the lifetime of the machine and may lead to serious failure, so that the efficient cooling system is needed. A new smart generation cooling system can be achieved by utilizing nanofluids. Nanofluids are dilute liquid suspension of nanoparticles with at least one of their principal dimensions smaller than $100 \mathrm{~nm}$. Nanofluids are proposed by Choi [1]. Nanoparticles are basically metal $\left(\mathrm{Cu}, \mathrm{Ni}, \mathrm{Al}\right.$, etc.), oxides $\left(\mathrm{Al}_{2} \mathrm{O}_{3}, \mathrm{TiO}_{2}, \mathrm{CuO}, \mathrm{SiO}_{2}\right.$, $\mathrm{Fe}_{2} \mathrm{O}_{3}, \mathrm{Fe}_{3} \mathrm{O}_{4}, \mathrm{BaTiO}_{3}$, etc.), and some other compounds (AlN, $\mathrm{SiC}, \mathrm{CaCO}_{3}$, graphene, etc.) and base fluids usually include water, ethylene glycol, propylene glycol, engine oil, and so forth. Due to very small sizes and large specific surface areas of the nanoparticles, nanofluids have superior properties like high thermal conductivity, minimal clogging in flow passages, long-term stability, and homogeneity. Application of nanofluids had been reviewed intensively by Yu and Xie [2] . Some theoretical and experimental studies can be found in the literature related to convective heat transfer enhancement by utilizing nanofluids, but for a configuration not closely similar to this work. The review of the rotating cubic and rectangular enclosures problem will be given first.

Buehler and Oertel [3] studied thermal cellular convection in a rotating rectangular box and found that the roll cells changed orientation with increasing Taylor number. The fluid flow and heat transfer characteristics of a rotating square enclosure were studied experimentally and numerically by Hamady et al. [4]. They concluded that the Coriolis force arising from rotation may have a remarkable influence on heat transfer when compared with nonrotating results and correlations of Nusselt number as functions of Taylor and Rayleigh number were built. Lee and Lin [5] and Ker and Lin $[6,7]$ studied a differentially heated rotating cubic enclosure. A significant flow modification was obtained when the rotational Rayleigh number is greater than the Rayleigh 
number or when the Taylor number is greater than the Rayleigh number. They also examined the effect of rotation on flow stabilization. A significant increase or decrease in heat transfer in a rotating and differentially heated square enclosure could be achieved due to rotational effects as reported by Baig and Masood [8] and Baig and Zunaid [9]. Jin et al. [10] studied numerically the rectangular enclosure with discrete heat sources and found that rotation results in imbalance of clockwise and counterclockwise circulations, increases heat transfer in the worst stage, reduces the oscillation of Nusselt number, and improves or reduces mean performance in each cycle. The effects of Coriolis force, centrifugal force, and thermal buoyancy force were segregated numerically by Tso et al. [11] on a differentially heated square enclosure. The effects of the Coriolis and centrifugal forces were found small and differentiated from those of other forces.

Natural convection studies of nanofluids in a square enclosure had been investigated by Khanafer et al. [12]. They showed that heat transfer coefficient increases with increasing $\mathrm{Cu}$ nanoparticles concentration. Oztop et al. [13] observed the heat transfer coefficient increases by adding $\mathrm{CuO}$ nanoparticles concentration in an inclined nonuniformly heated enclosure. On the other hand, Hwang et al. [14], Santra et al. [15] and Abu-Nada [16] reported a decrease in the heat transfer by increasing the nanoparticles concentration for a particular Rayleigh number. Ho et al. [17] investigated the effects of uncertainties due to adopting different formulas for the ratio thermal conductivity and dynamic viscosity for water $\mathrm{Al}_{2} \mathrm{O}_{3}$ nanofluids. They found that the heat transfer could be enhanced or mitigated depending on the formulas used for the estimated dynamic viscosity of the nanofluids. Recently, Qi et al. [18] and $\mathrm{He}$ et al. [19] found that the flow and heat transfer characteristics nanofluid were more sensitive to viscosity than to thermal conductivity.

In the present study, the problem of natural convection heat transfer in a rotating, differentially heated enclosure filled with nanofluids water-Ag, water- $\mathrm{Cu}$, water- $\mathrm{Cu}$, water$\mathrm{Al}_{2} \mathrm{O}_{3}$, and water- $\mathrm{TiO}_{2}$ is studied numerically. The effects of the nanoparticles types and concentration as well as the rotational speeds on characteristics of fluid and temperature field as well as heat transfer rate are considered. The numerical results of this study are thought to be useful in the design of an effective cooling system for rotating electrical machine to help ensure effective and safe operational conditions.

\section{Mathematical Formulation}

A schematic diagram of a square enclosure of side $\ell$ executes a steady uniform counterclockwise angular velocity about horizontal axis as shown in Figure 1, with the geometric layout and the Cartesian coordinates $(x, y)$ rotating with the enclosure. The fluid in the enclosure is a water-based nanofluids containing $\mathrm{Ag}, \mathrm{Cu}, \mathrm{Al}_{2} \mathrm{O}_{3}$, or $\mathrm{TiO}_{2}$ nanoparticles. The surface at $y=\ell / 2$ has constant hot temperature $\left(T_{h}\right)$ and the surface at $y=-\ell / 2$ has a constant cold temperature $\left(T_{c}\right)$. The temperatures along the lateral wall are assumed to be linearly distributed between $T_{h}$ and $T_{c}$ to consider conjugate heat transfer in the lateral wall of the experiments.
The $\varphi$ shown in Figure 1 is defined as an angular position. The Boussinesq approximation is used for natural convection and its validation in the rotation situation can be seen in [3]. The terms representing the thermal and rotational buoyancies and Coriolis force are, respectively, equal to $\rho_{\mathrm{nf}} \mathbf{g} \beta_{\mathrm{nf}}\left(T-T_{c}\right)$, $-\rho_{\mathrm{nf}} \mathbf{g} \beta_{\mathrm{nf}}\left(T-T_{c}\right) \boldsymbol{\Omega} \times(\boldsymbol{\Omega} \times \mathbf{r})$, and $-2 \rho_{\mathrm{nf}}\left[1-\beta_{\mathrm{nf}}\left(T-T_{c}\right)\right] \cdot \boldsymbol{\Omega} \times \mathbf{V}$. The continuity, momentum, and energy equations for the laminar flow development can be described as follows:

$$
\begin{aligned}
& \frac{\partial u}{\partial x}+\frac{\partial v}{\partial y}=0 \\
& \frac{\partial u}{\partial t}+u \frac{\partial u}{\partial x}+v \frac{\partial u}{\partial y} \\
& =-\frac{1}{\rho_{\mathrm{nf}}} \frac{\partial P_{m}}{\partial x}+\frac{\mu_{\mathrm{nf}}}{\rho_{\mathrm{nf}}}\left(\frac{\partial^{2} u}{\partial x^{2}}+\frac{\partial^{2} u}{\partial y^{2}}\right) \\
& +2 \boldsymbol{\Omega} v-2 \boldsymbol{\Omega} v \beta_{\mathrm{nf}}\left(T-T_{c}\right)-\mathbf{\Omega}^{2} \times \beta_{\mathrm{nf}}\left(T-T_{c}\right) \\
& +\mathbf{g} \beta_{\mathrm{nf}}\left(T-T_{c}\right) \sin (\boldsymbol{\Omega} t), \\
& \frac{\partial v}{\partial t}+u \frac{\partial v}{\partial x}+v \frac{\partial v}{\partial y} \\
& =-\frac{1}{\rho_{\mathrm{nf}}} \frac{\partial P_{m}}{\partial y}+\frac{\mu_{\mathrm{nf}}}{\rho_{\mathrm{nf}}}\left(\frac{\partial^{2} v}{\partial x^{2}}+\frac{\partial^{2} v}{\partial y^{2}}\right) \\
& -2 \Omega u+2 \boldsymbol{\Omega} u \beta_{\mathrm{nf}}\left(T-T_{c}\right)-\mathbf{\Omega}^{2} y \beta_{\mathrm{nf}}\left(T-T_{c}\right) \\
& +\mathbf{g} \beta_{\mathrm{nf}}\left(T-T_{c}\right) \cos (\boldsymbol{\Omega} t) \\
& \frac{\partial T}{\partial t}+u \frac{\partial T}{\partial x}+v \frac{\partial T}{\partial y}=\alpha_{\mathrm{nf}}\left(\frac{\partial^{2} T}{\partial x^{2}}+\frac{\partial^{2} T}{\partial y^{2}}\right),
\end{aligned}
$$

where $P_{m}$ is the motion pressure defined as

$$
\begin{aligned}
P_{m}= & p-\frac{1}{2} \rho_{\mathrm{nf}} \mathbf{\Omega}^{2} x^{2}-\frac{1}{2} \rho_{\mathrm{nf}} \mathbf{\Omega}^{2} y^{2} \\
& +\rho_{\mathrm{nf}} \mathbf{g} x \sin (\Omega t)+\rho_{\mathrm{nf}} \mathbf{g} y \cos (\boldsymbol{\Omega} t) .
\end{aligned}
$$

Hence,

$$
\begin{gathered}
-\frac{\partial P_{m}}{\partial x}=-\frac{\partial p}{\partial x}+\rho_{\mathrm{nf}} \boldsymbol{\Omega}^{2} x-\rho_{\mathrm{nf}} \mathbf{g} \sin (\boldsymbol{\Omega} t), \\
-\frac{\partial P_{m}}{\partial y}=-\frac{\partial p}{\partial y}+\rho_{\mathrm{nf}} \boldsymbol{\Omega}^{2} y-\rho_{\mathrm{nf}} \mathbf{g} \cos (\boldsymbol{\Omega} t) .
\end{gathered}
$$

The effective density of the nanofluids, $\rho_{\mathrm{nf}}$, is given as

$$
\rho_{\mathrm{nf}}=(1-\phi) \rho_{\mathrm{bf}}+\phi \rho_{\mathrm{sp}}
$$

and $\phi$ is the solid volume fraction of nanoparticles. Thermal diffusivity of the nanofluids is

$$
\alpha_{\mathrm{nf}}=\frac{k_{\mathrm{nf}}}{(\rho \mathrm{Cp})_{\mathrm{nf}}}
$$

where the heat capacitance of the nanofluids given is

$$
(\rho \mathrm{Cp})_{\mathrm{nf}}=(1-\phi)(\rho \mathrm{Cp})_{\mathrm{bf}}+\phi(\rho \mathrm{Cp})_{\mathrm{sp}} .
$$




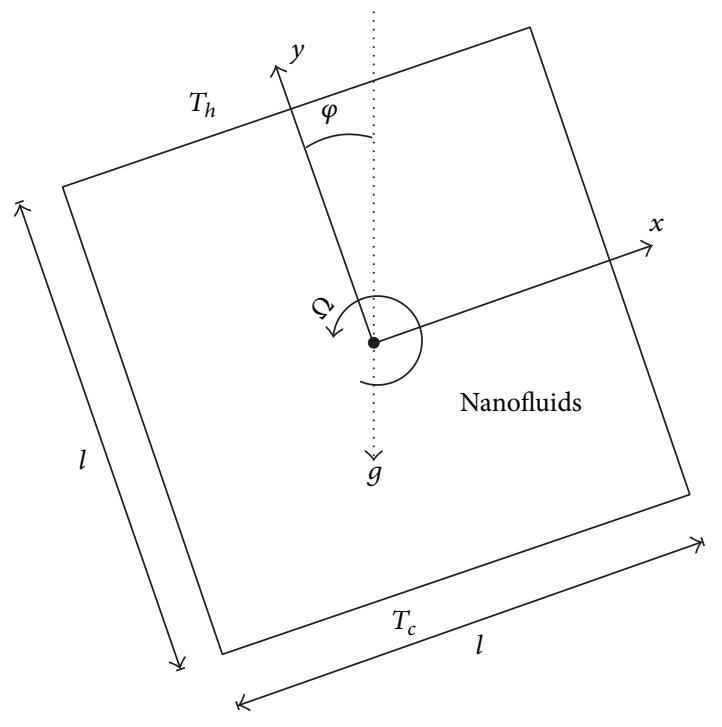

FIGURE 1: Schematic representation of the model.

The thermal expansion coefficient of the nanofluids can be determined by

$$
\beta_{\mathrm{nf}}=(1-\phi) \beta_{\mathrm{bf}}+\phi \beta_{\mathrm{sp}} .
$$

The governing equation (1) can be converted to nondimensional forms using the following nondimensional parameters:

$$
\begin{gathered}
X=\frac{x}{\ell}, \quad Y=\frac{y}{\ell}, \quad \tau=\frac{t \alpha_{\mathrm{bf}}}{\ell^{2}}, \quad U=\frac{u \ell}{\alpha_{\mathrm{bf}}}, \\
V=\frac{\nu \ell}{\alpha_{\mathrm{bf}}}, \quad \Theta=\frac{T-T_{c}}{T_{h}-T_{c}}, \quad \operatorname{Pr}_{\mathrm{bf}}=\frac{\nu_{\mathrm{bf}}}{\alpha_{\mathrm{bf}}} \\
\mathrm{Ra}_{\mathrm{bf}}=\frac{g \beta_{\mathrm{bf}}\left(T_{h}-T_{c}\right) \ell^{3}}{\nu_{\mathrm{bf}} \alpha_{\mathrm{bf}}}, \quad P=\frac{P_{m} \ell^{2}}{\rho_{\mathrm{nf}} \alpha_{\mathrm{bf}}^{2}} \\
\left(\mathrm{Ra}_{\omega}\right)_{\mathrm{bf}}=\frac{\beta_{\mathrm{bf}} \Omega^{2}\left(T_{h}-T_{c}\right) \ell^{4}}{\nu_{\mathrm{bf}} \alpha_{\mathrm{bf}}}, \quad \mathrm{Ta}_{\mathrm{bf}}=\frac{4 \Omega^{2} \ell^{4}}{\nu_{\mathrm{bf}}^{2}} .
\end{gathered}
$$

The Coriolis buoyancy force is neglected, because $\mid \beta_{\mathrm{nf}}(T-$ $\left.T_{c}\right) \mid \ll 1$ in the present studies. The nondimensional continuity, momentum, and energy equations are written as follows:

$$
\begin{gathered}
\frac{\partial U}{\partial X}+\frac{\partial V}{\partial Y}=0 \\
\frac{\partial U}{\partial \tau}+U \frac{\partial U}{\partial X}+V \frac{\partial U}{\partial Y} \\
=-\frac{\partial P}{\partial X}+\operatorname{Pr}_{\mathrm{bf}} \frac{\rho_{\mathrm{bf}}}{\rho_{\mathrm{nf}}} \frac{\mu_{\mathrm{nf}}}{\mu_{\mathrm{bf}}} \\
\times\left(\frac{\partial^{2} U}{\partial X^{2}}+\frac{\partial^{2} U}{\partial Y^{2}}\right)+\underbrace{\operatorname{Ta}_{\mathrm{bf}}^{0.5} \operatorname{Pr}_{\mathrm{b}} V}_{\text {Coriolis force term }} \\
-\operatorname{Pr}_{\mathrm{bf}} \frac{\rho_{\mathrm{bf}}}{\rho_{\mathrm{nf}}}\left(1-\phi+\phi \frac{\rho_{\mathrm{sp}} \beta_{\mathrm{sp}}}{\rho_{\mathrm{bf}} \beta_{\mathrm{bf}}}\right)
\end{gathered}
$$

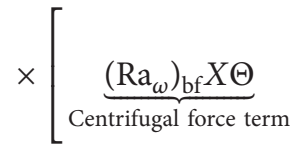

$$
-\underbrace{\mathrm{Ra}_{\mathrm{bf}} \Theta \sin \left(0.5 \mathrm{Ta}_{\mathrm{bf}}^{0.5} \operatorname{Pr}_{\mathrm{bf}} \tau\right)}_{\text {Buoyancy force term }}] \text {, }
$$$$
\frac{\partial V}{\partial \tau}+U \frac{\partial V}{\partial X}+V \frac{\partial V}{\partial Y}
$$$$
=-\frac{\partial P}{\partial Y}+\operatorname{Pr}_{\mathrm{bf}} \frac{\rho_{\mathrm{bf}}}{\rho_{\mathrm{nf}}} \frac{\mu_{\mathrm{nf}}}{\mu_{\mathrm{bf}}}
$$$$
\times\left(\frac{\partial^{2} V}{\partial X^{2}}+\frac{\partial^{2} V}{\partial Y^{2}}\right)-\underbrace{\mathrm{Ta}_{\mathrm{bf}}^{0.5} \operatorname{Pr}_{\mathrm{bf}} U}_{\text {Coriolis force term }}
$$$$
-\operatorname{Pr}_{\mathrm{bf}} \frac{\rho_{\mathrm{bf}}}{\rho_{\mathrm{nf}}}\left(1-\phi+\phi \frac{\rho_{\mathrm{sp}} \beta_{\mathrm{sp}}}{\rho_{\mathrm{bf}} \beta_{\mathrm{bf}}}\right)
$$

$$
\times[\underbrace{\left(\mathrm{Ra}_{\omega}\right)_{\mathrm{bf}} Y \Theta}_{\text {Centrifugal force term }}
$$

$$
-\underbrace{\operatorname{Ra}_{\mathrm{bf}} \Theta \cos \left(0.5 \mathrm{Ta}_{\mathrm{bf}}^{0.5} \operatorname{Pr}_{\mathrm{bf}} \tau\right)}_{\text {Buoyancy force term }}] \text {, }
$$

$$
\frac{\partial \Theta}{\partial \tau}+U \frac{\partial \Theta}{\partial X}+V \frac{\partial \Theta}{\partial Y}=\frac{k_{\mathrm{nf}}}{k_{\mathrm{bf}}} \frac{(\rho \mathrm{Cp})_{\mathrm{bf}}}{(\rho \mathrm{Cp})_{\mathrm{nf}}}\left(\frac{\partial^{2} \Theta}{\partial X^{2}}+\frac{\partial^{2} \Theta}{\partial Y^{2}}\right),
$$

where $U=V=0$ on the walls and the boundary conditions for the nondimensional temperatures are

$$
\begin{aligned}
& \Theta=Y+0.5 \text { at } X=-0.5, \\
& \Theta=Y+0.5 \text { at } X=0.5, \\
& \Theta=0 \quad \text { at } Y=-0.5, \\
& \Theta=1 \text { at } Y=0.5 .
\end{aligned}
$$

The nondimensional governing equations contain three independent dimensionless parameters, namely, Prandtl number, Rayleigh number, and Taylor number. In addition, rotational Rayleigh number reflects the effect of centrifugal buoyancy force, but it depends on the other dimensionless parameters too [11].

The ratio dynamic viscosity of the nanofluids given by Brinkman [21] is

$$
\frac{\mu_{\mathrm{nf}}}{\mu_{\mathrm{bf}}}=\frac{1}{(1-\phi)^{2.5}} .
$$

The ratio thermal conductivity of nanofluids restricted to spherical nanoparticles is approximated by the MaxwellGarnetss (MG) [20] model

$$
\frac{k_{\mathrm{nf}}}{k_{\mathrm{bf}}}=\frac{k_{\mathrm{sp}}+2 k_{\mathrm{bf}}-2 \phi\left(k_{\mathrm{bf}}-k_{\mathrm{sp}}\right)}{k_{\mathrm{sp}}+2 k_{\mathrm{bf}}+\phi\left(k_{\mathrm{bf}}-k_{\mathrm{sp}}\right)} .
$$


TABLE 1: Thermophysical properties of water with $\mathrm{Cu}$ [12], $\mathrm{Al}_{2} \mathrm{O}_{3}$ [17], $\mathrm{Ag}$, and $\mathrm{TiO}_{2}$ [20].

\begin{tabular}{lccccc}
\hline Physical properties & Water & $\mathrm{Ag}$ & $\mathrm{Cu}$ & $\mathrm{AL}_{2} \mathrm{O}_{3}$ & 765 \\
$\mathrm{Cp}(\mathrm{J} / \mathrm{kg} \mathrm{K})$ & 4179 & 235 & 383 & $\mathrm{TiO}_{2}$ \\
$\rho\left(\mathrm{kg} / \mathrm{m}^{3}\right)$ & 997.1 & 10500 & 8954 & 3600 & 486.2 \\
$k\left(\mathrm{~W} \mathrm{~m}^{-1} \mathrm{~K}^{-1}\right)$ & 0.6 & 429 & 400 & 46 & 4250 \\
$\beta \times 10^{-5}(1 / \mathrm{K})$ & 21 & 5.4 & 1.67 & 0.63 & 8.954 \\
\hline
\end{tabular}

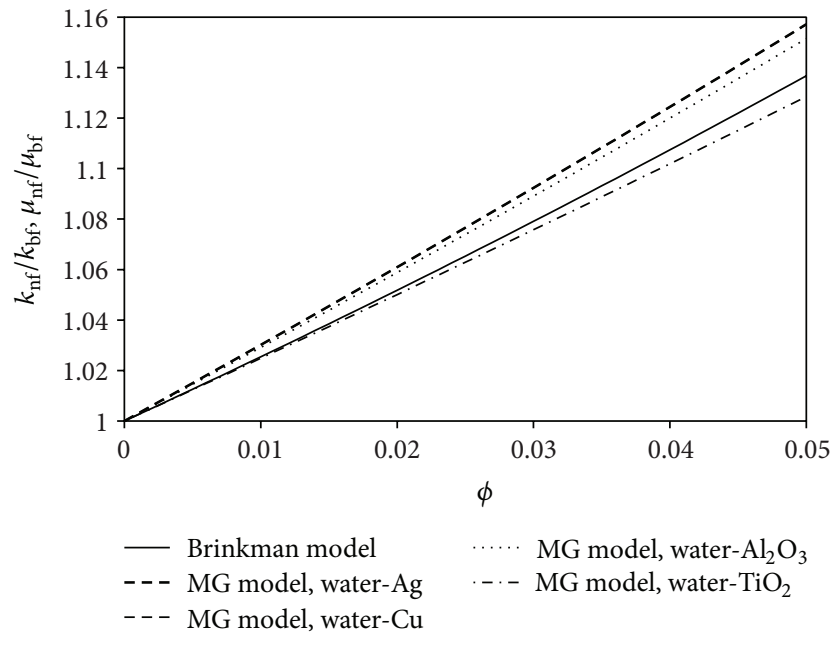

FIGURE 2: The ratio thermal conductivity of water-Ag, water- $\mathrm{Cu}$, water- $\mathrm{Al}_{2} \mathrm{O}_{3}$, and water- $\mathrm{TiO}_{2}$ using Maxwell-Garnett model and the ratio dynamical viscosity using Brinkman model versus volume fraction.

The viscosity and conductivity of the nanofluids are integrated in Figure 2 and the physical properties of the water and nanoparticles are given in Table 1.

The fluid motion is displayed using the stream function $\Psi$ obtained from velocity components $U$ and $V$. The relationships between the stream function and the velocity components are $U=\partial \Psi / \partial Y$ and $V=-\partial \Psi / \partial X$, which yield a single equation,

$$
\frac{\partial^{2} \Psi}{\partial X^{2}}+\frac{\partial^{2} \Psi}{\partial Y^{2}}=\frac{\partial U}{\partial Y}-\frac{\partial V}{\partial X},
$$

where $\Psi=0$ at all walls of the enclosure. The physical quantities of interest in this problem are the average Nusselt number, representation of the average heat transfer rate on the heated or cooled plates that is defined by

$$
\overline{\mathrm{Nu}}=\int_{-0.5}^{0.5}\left[\left(\frac{k_{\mathrm{nf}}}{k_{\mathrm{bf}}}\right) \frac{\partial \Theta}{\partial Y}\right] \mathrm{d} X .
$$

The time-integrated of the average heat transfer rate in one cycle is

$$
\overline{\overline{\mathrm{Nu}}}=\int_{0}^{\tau_{p}} \overline{\mathrm{Nu}} \mathrm{d} \tau
$$

\section{Numerical Method and Validation}

Staggered grid arrangement, together with Marker and Cell (MAC) method [22], is adopted to solve the governing equation (9) subject to the boundary conditions (10). Due to lack of boundary conditions for pressure, the use of the staggered grid and MAC formulation provided an advantage. That is, one may locate the secondary grid along the boundaries of the domain where only specification of velocity boundary conditions is required but not of the pressure. The fictitious values of velocity outside the domain are obtained by extrapolation of the interior points as given by Hoffmann and Chiang [23]. A second-order central difference approximation is used for the space discretization and a first-order approximation is used for temporal derivative. The solution of the Poisson pressure equation is obtained by applying an iterative Gaussian-SOR method. The velocities are then computed by the projection method.

In this study, the convergence criterion for the Poisson equation is set at $\epsilon=10^{-5}$ and the time stepping is chosen, $\Delta \tau=\lambda(1 / 4)(\Delta X)^{2} \operatorname{Pr}_{\mathrm{bf}}$ to meet stability criteria where $\lambda$ is the safety factor with a value between 0 and 1 . Uniform grid distribution is used for the whole enclosure. The effect of grid resolution was examined in order to select the appropriate grid density as demonstrated in Figure 3(a) for water- $\mathrm{Cu}$ nanofluids with volume fraction of $5 \%$ and $\mathrm{Ta}_{\mathrm{bf}}=$ $4.7 \times 10^{3}$ at $\varphi=\pi / 2$. The results indicate that an $120 \times$ 120 mesh can be used in the final computations. A typical computation process for the present periodic oscillation problem is shown in Figure 3(b) where, after two rotations, the final periodic oscillation of the $\overline{\mathrm{Nu}}$ is obtained. Therefore, all the computations reported in this work were carried out beyond two rotations. As a validation, our results for the isotherms compare well with those obtained by Hamady et al. [4] and Tso et al. [11] for a pure fluid, $\operatorname{Pr}=0.7, \mathrm{Ra}=1.2 \times 10^{5}$, $\mathrm{Ta}=8.9 \times 10^{4}$, and $\Omega=8.5 \mathrm{rpm}$ as shown in Figure 4 .

\section{Results and Discussion}

The analyses in the undergoing numerical investigation are performed in the following range of the associated dimensionless groups: the solid volume fraction, $0.0 \leq \phi \leq$ 0.05 , and the Taylor number for the base fluid, $8 \times 10^{2} \leq$ $\mathrm{Ta}_{\mathrm{bf}} \leq 2 \times 10^{4}$ as tabulated in Table 2 . The Prandtl number and the Rayleigh number are fixed at $\operatorname{Pr}_{b f}=6.2$ and $\mathrm{Ra}_{\mathrm{bf}}=4.62 \times 10^{5}$, respectively. The rotational Rayleigh number, $\left(\mathrm{Ra}_{\omega}\right)_{\mathrm{bf}}$, reflecting centrifugal buoyancy force was not discussed except to specify it explicitly. This is due to the fact that the $\left(\mathrm{Ra}_{\omega}\right)_{\mathrm{bf}}$ is not being an independent parameter but depending on $\operatorname{Pr}_{\mathrm{bf}}, \mathrm{Ra}_{\mathrm{bf}}$, and $\mathrm{Ta}_{\mathrm{bf}}$. It worth mentioning that in the present research, the buoyancy force is stronger than Coriolis forces and the Coriolis force is greater the centrifugal force. Present work will also compare utilization 


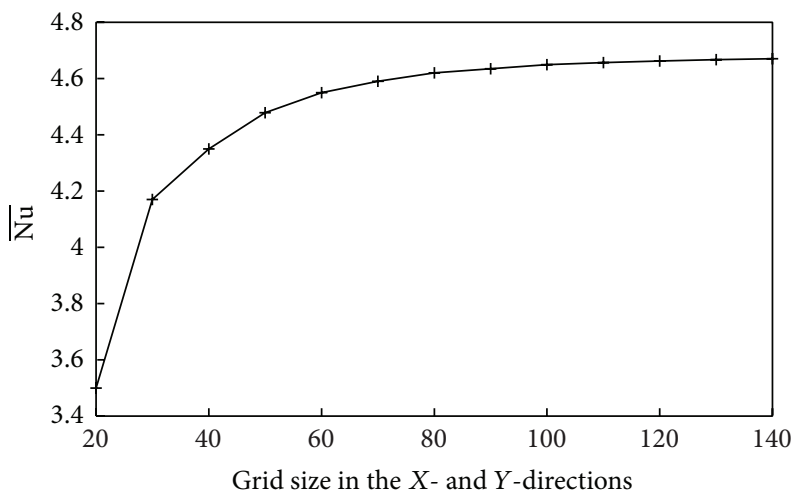

(a)

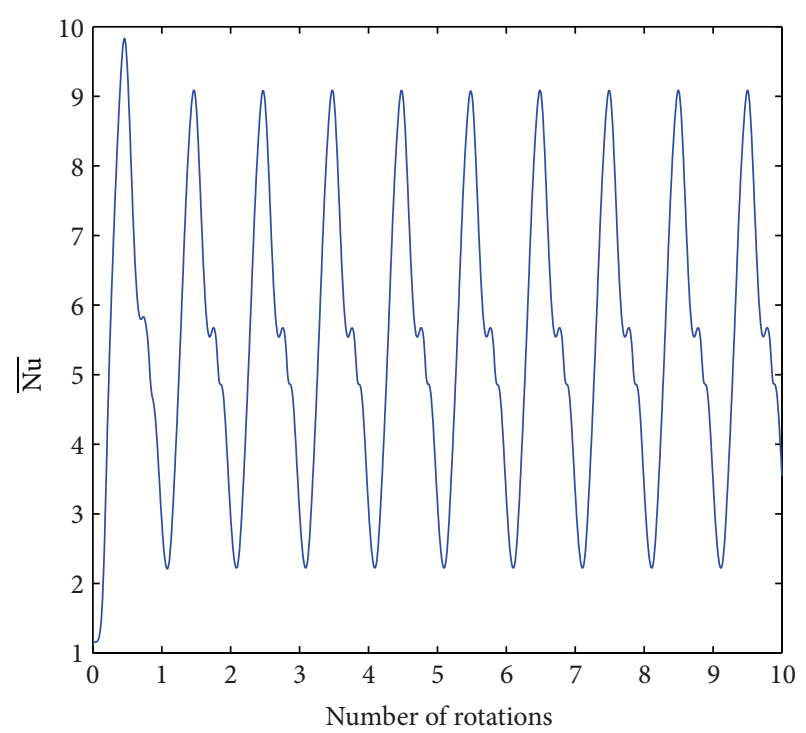

(b)

FIGURE 3: (a) Grid independency study: $\overline{\mathrm{Nu}}$ versus number of grid points for $\phi=0.05$ and $\mathrm{Ta}_{\mathrm{bf}}=4.7 \times 10^{3}$ at $\varphi=\pi / 2$; (b) typical computation process for present periodic oscillation problem.

TABLE 2: Fixed variables and constants.

\begin{tabular}{lc}
\hline Parameter symbol & Magnitude \\
\hline$\phi$ & $0-5(\%)$ \\
$T_{h}$ & $282(\mathrm{~K})$ \\
$T_{c}$ & $273(\mathrm{~K})$ \\
$\ell$ & $0.006(\mathrm{~m})$ \\
$\mathrm{Pr}_{\mathrm{bf}}$ & 6.2 \\
$\mathrm{Ra}_{\mathrm{bf}}$ & $4.62 \times 10^{5}$ \\
$\Omega$ & $3.5-17.5(\mathrm{rpm})$ \\
$\left(\mathrm{Ra}_{\omega}\right)_{\mathrm{bf}}$ & $38-950.3$ \\
$\mathrm{Ta}_{\mathrm{bf}}$ & $8 \times 10^{2}-2 \times 10^{4}$ \\
\hline
\end{tabular}

of different nanoparticles that is, $\mathrm{Ag}, \mathrm{Cu}, \mathrm{Al}_{2} \mathrm{O}_{3}$, or $\mathrm{TiO}_{2}$ as specified in Table 1 . The flow and temperature fields of nanofluids and base fluid during rotation will be shown in Figures 5 and 6 . The average Nusselt number over one period will be presented in Figures 7 and 8. Finally, plots of the time-integrated average Nusselt number will be displayed in Figures 10 and 9.

Figures $5(a)-5(h)$ show the effects of rotation on the flow field for water- $\mathrm{Cu}$ nanofluids with volume fraction $5 \%$ and the pure water with $\mathrm{Ta}_{\mathrm{bf}}=4.7 \times 10^{3}$. There are two basic flow structures, clockwise (negative sign) and counterclockwise (positive sign) circulations, depending on the heated position as well as the body forces. The fully clockwise circulations were obtained in Figures 5(a)-5(h). These circulations are induced by the buoyancy force. The weak counterclockwise flows due to the Coriolis force then appear in the upperleft and lower-right corners of the enclosure at Figure 5(e), heating from below. When $\varphi>\pi / 2$, the gravitational buoyancy force now induces a counterclockwise circulation. However the flow inertia from the clockwise circulation still persists and puts off the transition angle for flow reversal and this flow is aided by the Coriolis force on the other hand. Therefore, the clockwise and the counterclockwise flow compete with each other as displayed at Figure 5(f). The large vortex driven is by Coriolis force and a smaller vortex is driven by thermal buoyancy force. In Figure 5(g), the clockwise flow totally disappears and replaces the counterclockwise, unicellular motion flow as the angle of the gravitational force increases. This is due to the fact that buoyancy force balances the effect of the Coriolis force in the clockwise circulation. Finally, in Figure 5(h), the transition from clockwise to counterclockwise motion is completed, where the Coriolis force is directed outwards from the core that suppressed the flow. It should have made clear that this sequence repeats itself, the fully clockwise flow then transition flow, and totally counterclockwise flow. It observed that, during rotation, the strength of the flow circulation of nanofluids is always stronger than the base fluid. It observed the flow patterns between the nanofluids and pure water were different enough in some angular locations. It also observed that the streamlines of the nanofluids and pure water in all of Figures $5(\mathrm{a})-5(\mathrm{~h})$ present centrosymmetry shape.

Figures 6(a)-6(h) exhibit the effects of rotation on the temperature field for water- $\mathrm{Cu}$ nanofluids with volume fraction of $5 \%$ and the pure water with $\mathrm{Ta}_{\mathrm{bf}}=4.7 \times 10^{3}$. The heated wall positions move according to the angular position. Starting from $\varphi=\pi / 4$ where the heated wall is above the cold wall, the fluid temperatures adjoining the hot wall rise. The fluid moves due to buoyancy force from the left region the right region and creates a clockwise circulation cell as shown in the previous figure. Denser boundary layers near the hot and cold walls were formed as the rotational angle takes higher up to $\varphi=\pi$. This due to the fact that the Coriolis is directed into the core region that leads to stronger flow 

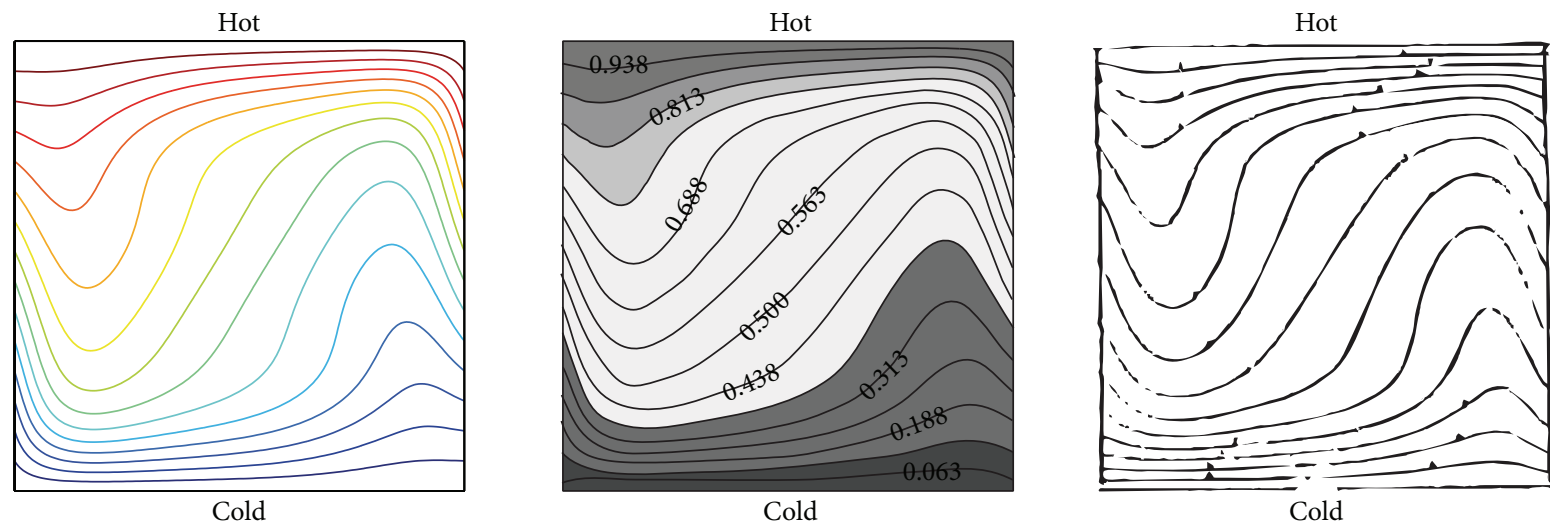

(a) $\varphi=0$
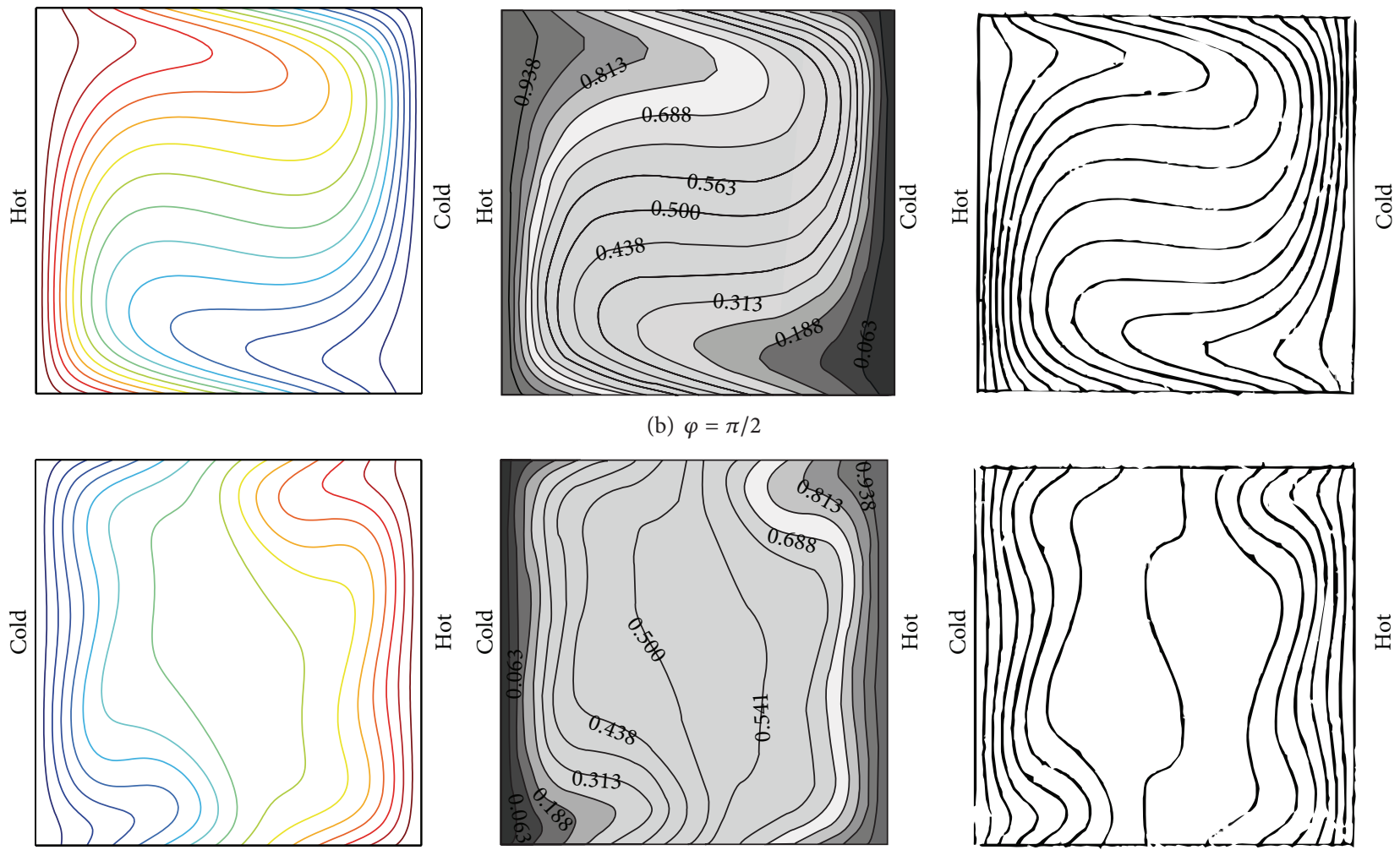

(c) $\varphi=3 \pi / 2$

FIGURE 4: Comparison of computed isotherms of present work (left) with Tso et al. [11] (middle) and Hamady et al. [4] (right) results in $\mathrm{Pr}=0.7, \mathrm{Ra}=1.2 \times 10^{5}, \mathrm{Ta}=8.9 \times 10^{4}$, and $\Omega=8.5 \mathrm{rpm}$.

circulation and then higher temperature gradient near the walls. Later, the temperature gradient near the walls decreases by increasing the rotational angle. This due to the fact that the Coriolis force is directed outwards from the core and tends to stabilize, thus reducing the heat transfer on the wall. The heat transfer rate of the nanofluids is always higher than the base fluid at any angular position. This is due to the fact that, at any locations, nanofluid has higher thermal conductivity leading to higher energy, which accelerates the flow. Actually, this phenomenon is also accompanied by an undesirable effect promoted by higher viscosity that suppresses the flow but is small compared to the favorable effect driven by the presence of the high thermal conductivity.

Figure 7 depicts the variation of the average Nusselt number, $\overline{\mathrm{Nu}}$, over one cycle for several rotational speeds (Taylor numbers) at $\phi=0.05$ and water- $\mathrm{Cu}$. The average Nusselt number profiles display different characteristics for the various Taylor numbers. It observed that increasing the Taylor number reduces the number of local maximum $\overline{\mathrm{Nu}}$, that is, four, three, two, and one local maximum for $\mathrm{Ta}_{\mathrm{bf}}=$ $8.0 \times 10^{2}, \mathrm{Ta}_{\mathrm{bf}}=2.0 \times 10^{3}, \mathrm{Ta}_{\mathrm{bf}}=4.7 \times 10^{3}$, and $\mathrm{Ta}_{\mathrm{bf}}=$ $2.0 \times 10^{4}$, respectively. The local maximums of the heat 


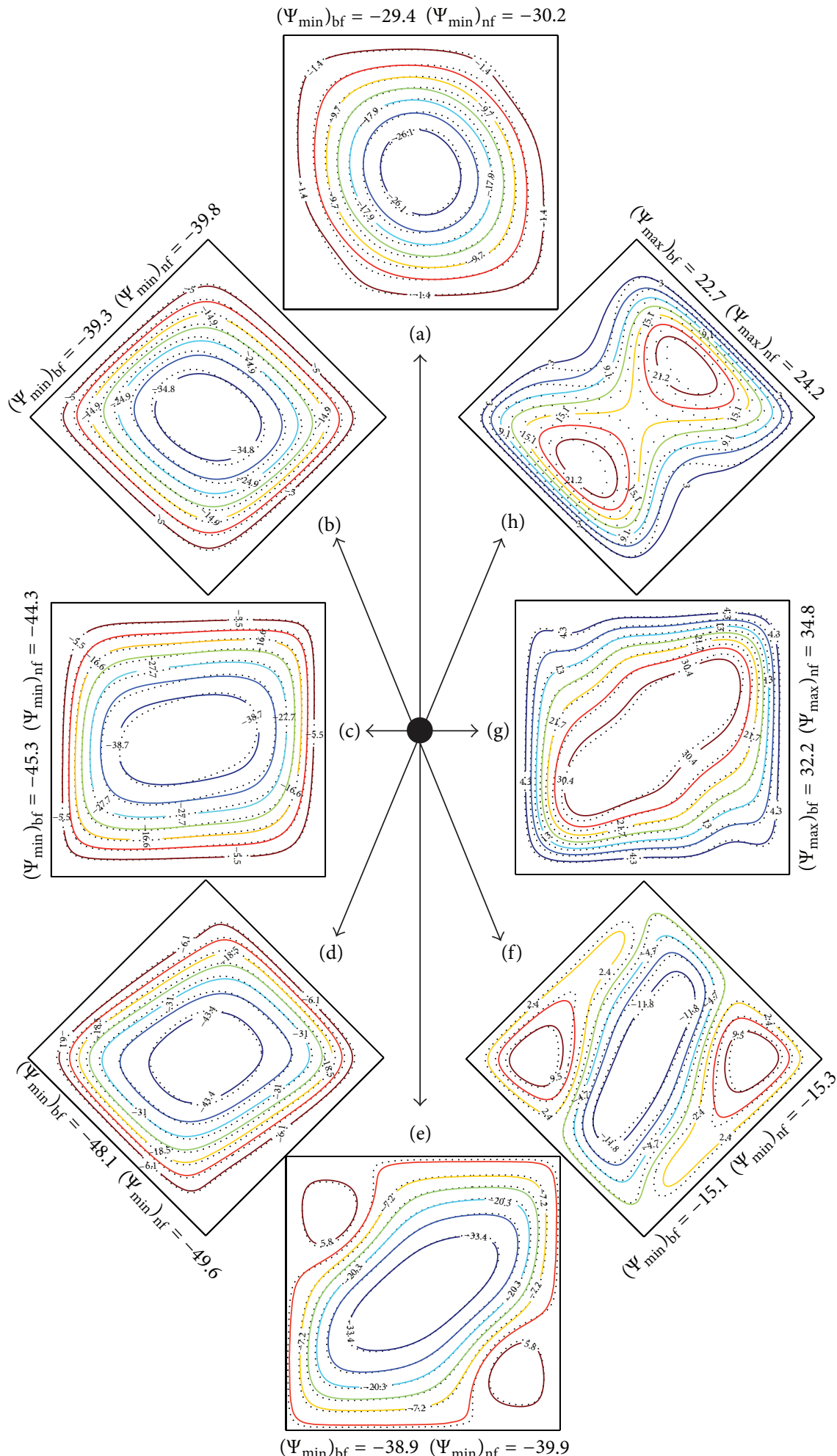

FIGURE 5: Streamlines (nanofluids (solid lines) with $\phi=0.05$ and pure-fluid (dashed lines)) evolution during one period for Ta $\mathrm{bf}_{\mathrm{bf}}=4.7 \times 10^{3}$ when (a) $\varphi=0$, (b) $\varphi=\pi / 4$, (c) $\varphi=\pi / 2$, (d) $\varphi=3 \pi / 4$, (e) $\varphi=\pi$, (f) $\varphi=5 \pi / 4$, (g) $\varphi=3 \pi / 2$, and (h) $\varphi=7 \pi / 4$. 


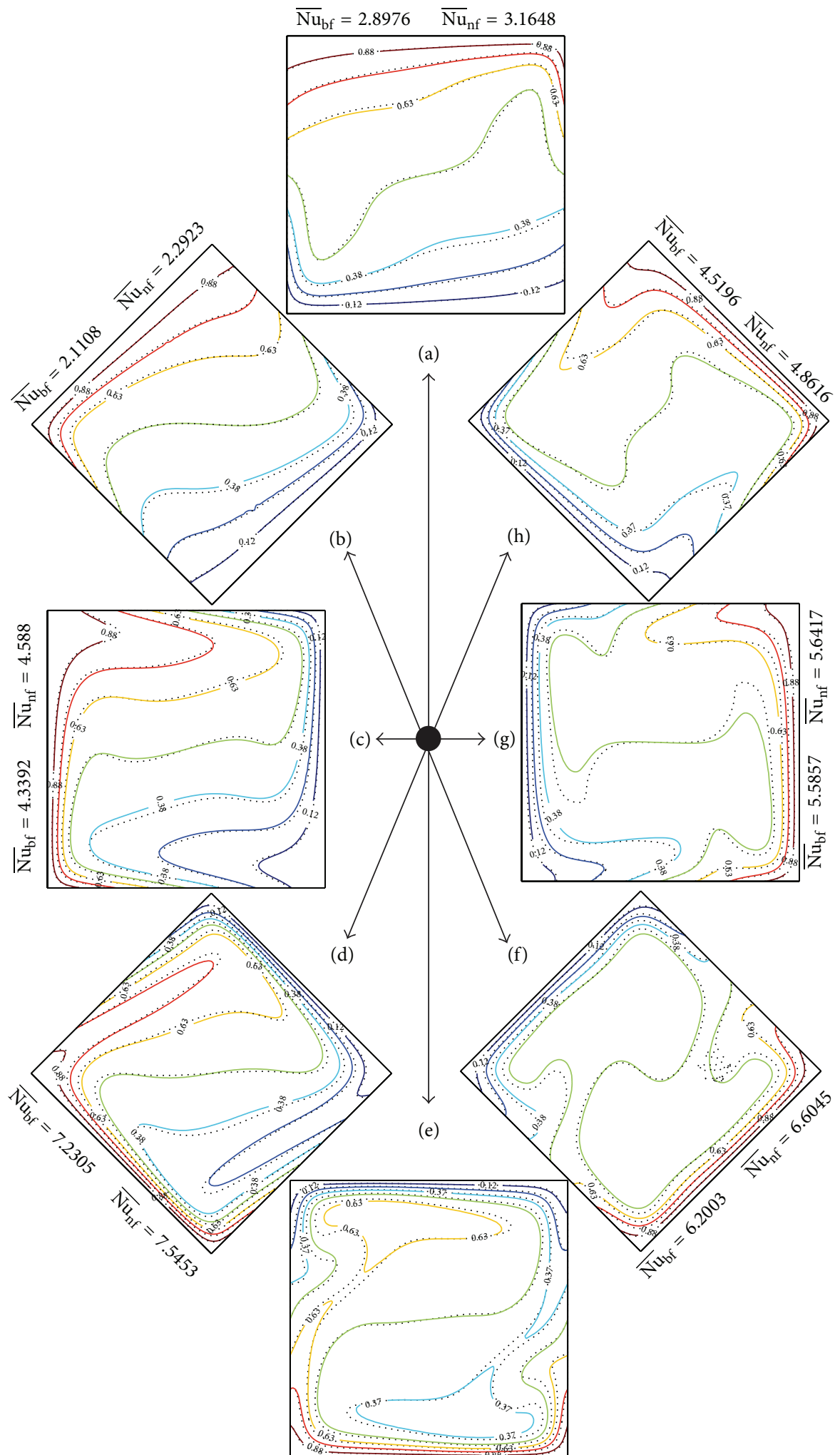

$\overline{\mathrm{Nu}}_{\mathrm{bf}}=8.5615 \quad \overline{\mathrm{Nu}}_{\mathrm{nf}}=9.0331$

FIGURE 6: Isotherms (nanofluids (solid lines) with $\phi=0.05$ and pure-fluid (dashed lines)) evolution during one period for Ta $\mathrm{b}_{\mathrm{bf}}=4.7 \times 10^{3}$ when (a) $\varphi=0$, (b) $\varphi=\pi / 4$, (c) $\varphi=\pi / 2$, (d) $\varphi=3 \pi / 4$, (e) $\varphi=\pi$, (f) $\varphi=5 \pi / 4$, (g) $\varphi=3 \pi / 2$, and (h) $\varphi=7 \pi / 4$. 


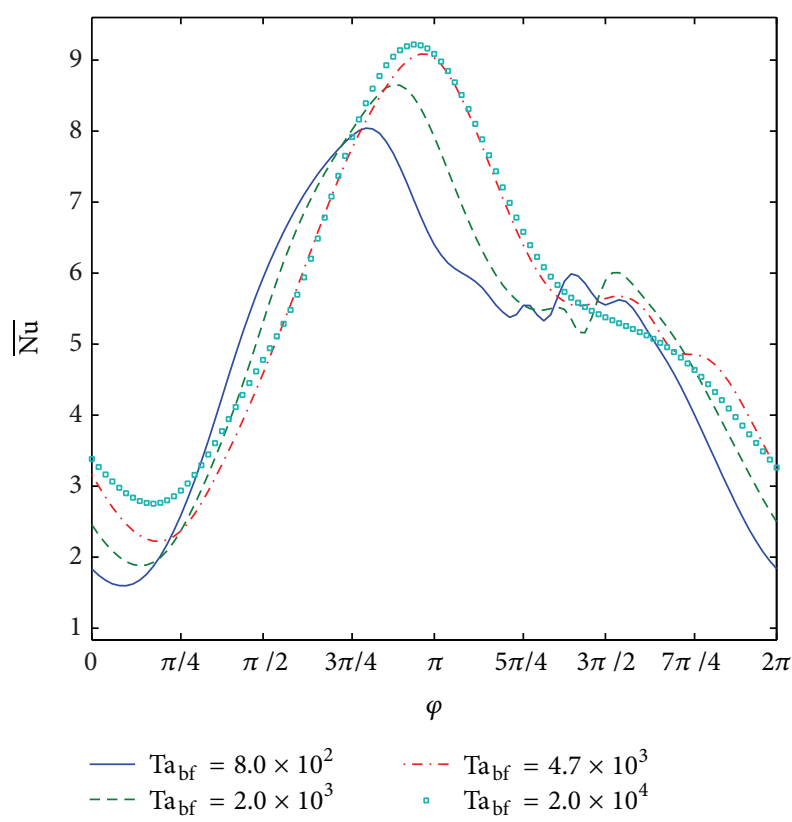

FIGURE 7: Plots of the average Nusselt number against $\varphi$ for the values of $\mathrm{Ta}_{\mathrm{bf}}$ labeled on the figure with $\phi=0.05$ for water-Cu.

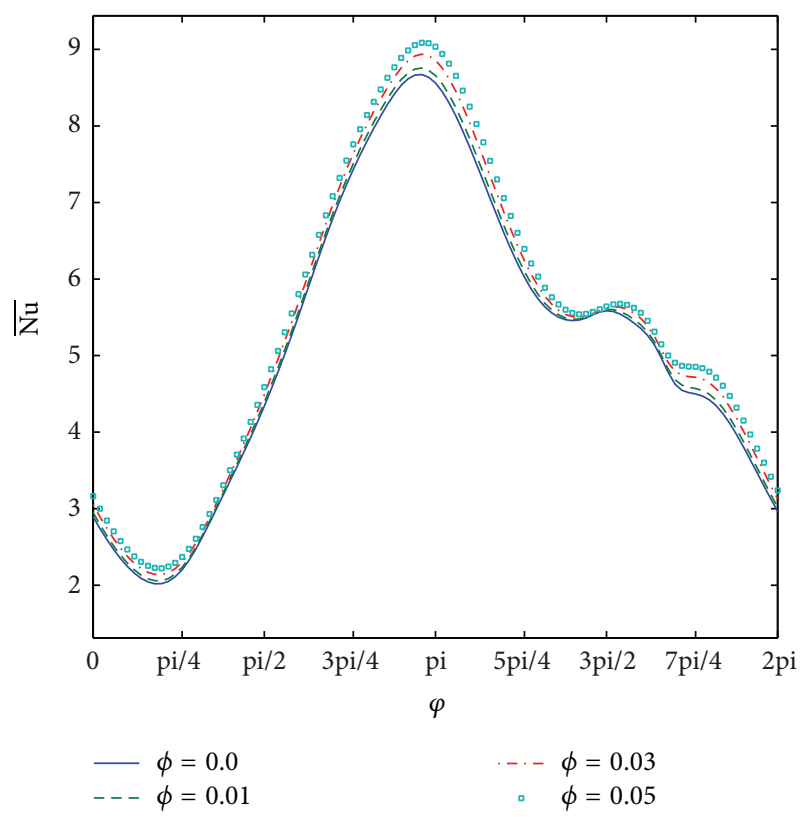

FIGURE 8: Plots of the average Nusselt number against $\varphi$ for the values of $\phi$ labeled on the figure with $\mathrm{Ta}_{\mathrm{bf}}=4.7 \times 10^{3}$ for water- $\mathrm{Cu}$.

transfer rate were located in the range from $3 \pi / 4$ to $13 \pi / 8$ where, in this interval, the Coriolis force has aiding effect on the buoyancy circulation. No secondary local maximum of $\overline{\mathrm{Nu}}$ was obtained at the highest rotational speeds. This situation happens because the velocities were kept under control by the Coriolis force at the highest rotational speeds.

The $\overline{\mathrm{Nu}}$ over one period for different $\mathrm{Cu}$ nanoparticles concentration at $\mathrm{Ta}_{\mathrm{bf}}=4.7 \times 10^{3}$ is presented in Figure 8 . The interaction of the gravitational and Coriolis forces

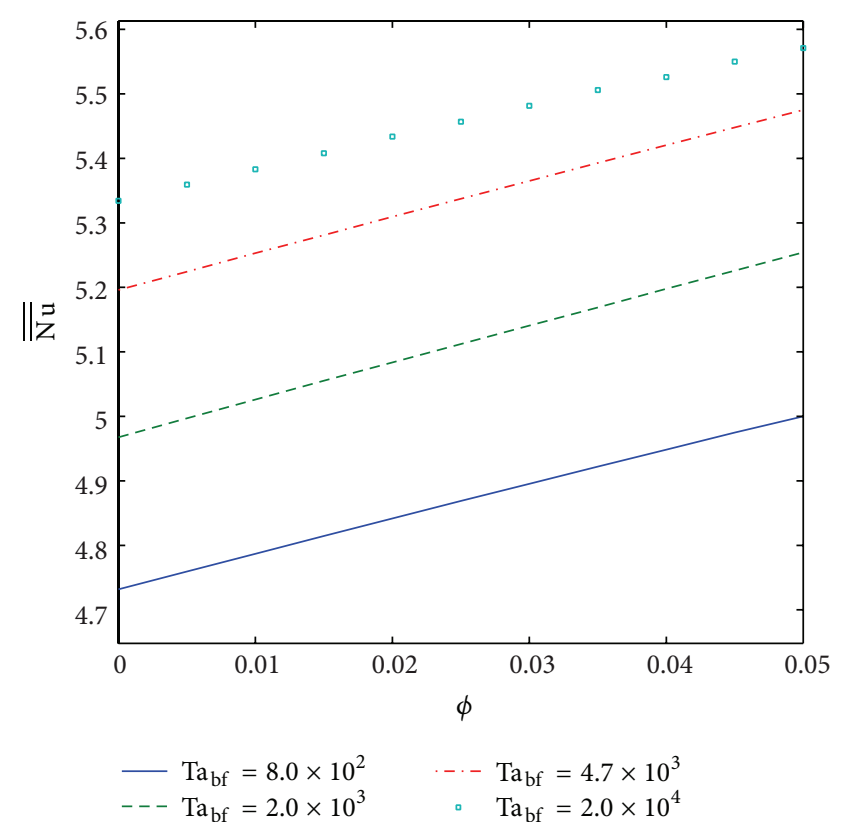

FIgURE 9: Plots of the time-integrated average Nusselt number against the volume fraction for the values of $\mathrm{Ta}_{\mathrm{bf}}$ labeled on the figure for water-Cu.

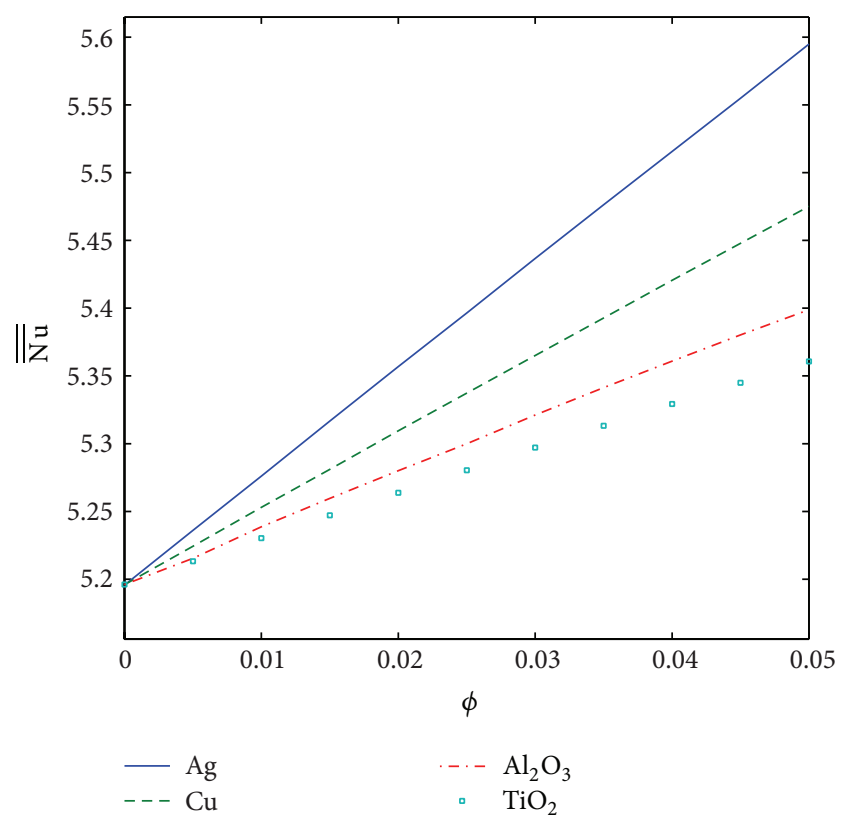

FIGURE 10: Plots of the time-integrated average Nusselt number against the volume fraction for different nanoparticles type at $\mathrm{Ta}_{\mathrm{bf}}=$ $4.7 \times 10^{3}$.

during rotation can increase or decrease the $\overline{\mathrm{Nu}}$ as discussed previously. The first peak heat transfer rate is due to the aiding effect of the Coriolis force and located near $\varphi=\pi$, the Bénard convection case. The second local maximum of the average Nusselt number located about $3 \pi / 2$ for the considered volume fraction. It observed that the significant effects of adding the nanoparticles were obtained at the first 
local maximum in the Nusselt number. The angular location of the first and second local maximum changed slightly by varying the $\phi$. The stagnant $\overline{\mathrm{Nu}}$ by increasing the fluid conductivity is also found in some angular locations. This due to at these locations and the flow is stabilized by the Coriolis force. The Coriolis force is directed outwards from the core that would decelerate the higher velocities promoted by the higher fluid conductivity, thus stagnating the heat transfer on the wall.

Figure 9 shows the time-integrated average Nusselt number of the water- $\mathrm{Cu}$ against the volume fraction for different Taylor numbers. The global heat transfer performance increases linearly by increasing the nanoparticles concentration. Higher rotational speeds of the nanofluids or pure water lead to better heat transfer rate. This finding agrees with the previous experimental result by Lin and Yan [24]. It should be better if we simulate for $\Omega>30 \mathrm{rpm}$, but higher rotational speeds at the higher Rayleigh number bring about difficulties in numerical simulation because of the instability of fluid motion. The $\overline{\overline{\mathrm{Nu}}}$ in Figure 9 displays monotone curves, where the $\overline{\overline{\mathrm{Nu}}}$ increases about $1.1 \%$ by increasing $1 \% \phi$ for each of rotational speeds.

Figure 10 displays the time-integrated average Nusselt number against the volume fraction for different nanoparticles types at $\mathrm{Ta}_{\mathrm{bf}}=4.7 \times 10^{3}$. The results demonstrated in this figure help compare the heat transfer appearance of the argentum $(\mathrm{Ag})$, copper $(\mathrm{Cu})$, alumina $\left(\mathrm{Al}_{2} \mathrm{O}_{3}\right)$, and titania $\left(\mathrm{TiO}_{2}\right)$ suspended in the rotating water. The lowest heat transfer rate was obtained for the $\mathrm{TiO}_{2}$ since the $\mathrm{TiO}_{2}$ has lower value of thermal conductivity ratio (see Figure 2 and Table 1) that leads to lower thermal energy and smaller enhancements in the heat transfer performance. As it can be seen in Figure 2, increasing $\phi$ will increase the ratio thermal conductivity monotonically that eventually leads to monotone increasing in the heat transfer rate as shown in Figure 10. The $\overline{\overline{\mathrm{Nu}}}$ increases about $1.5 \%, 1.1 \%, 0.8 \%$, and $0.6 \%$ by increasing $1 \% \phi$ of the $\mathrm{Ag}, \mathrm{Cu}, \mathrm{Al}_{2} \mathrm{O}_{3}$, and $\mathrm{TiO}_{2}$, respectively.

\section{Conclusions}

The present work has studied natural convection heat transfer characteristics and flow fields in a nanofluids-filled, differentially heated square enclosure. The enclosure was rotated above its longitudinal horizontal axis. The dimensionless forms of the governing equations were solved using the staggered grid arrangement together with MAC method. Detailed computational results for flow and temperature fields and the heat transfer performance have been presented in graphical forms. The periodic oscillation of the flow and temperature fields as well as the heat transfer was obtained. The main conclusions of the present analysis are as follows.

(a) A single primary flow circulation is obtained for the heating from the top and the sides. The flow circulation patterns between the nanofluids and pure water were different enough in some angular locations and it presented centrosymmetry shape during rotation. (b) The angular locations of the local maximums heat transfer are sensitive to rotational speeds and nanoparticles concentration.

(c) The higher nanoparticles concentration leads to better heat transfer rate for any rotational angles considered here. The global quantity of heat transfer rate increases about $1.5 \%, 1.1 \%, 0.8 \%$, and $0.6 \%$ by increasing $1 \% \phi$ of the $\mathrm{Ag}, \mathrm{Cu}, \mathrm{Al}_{2} \mathrm{O}_{3}$, and $\mathrm{TiO}_{2}$, respectively, for any rotational speeds.

The theoretical prediction in this paper is expected to be a useful guide for the experimentalists to study the effectiveness of utilizing nanofluids in the cooling system of the rotating equipment.

\section{Nomenclature}

Cp: $\quad$ Specific heat capacity $(\mathrm{J} / \mathrm{kg} \mathrm{K})$

$g: \quad$ Gravitational acceleration $\left(\mathrm{m} / \mathrm{s}^{2}\right)$

$k$ : $\quad$ Thermal conductivity $\left(\mathrm{W} \mathrm{m}^{-1} \mathrm{~K}^{-1}\right)$

$\ell: \quad \quad$ Width and height of enclosure $(\mathrm{m})$

Nu: $\quad$ Nusselt number

Ra: $\quad$ Rayleigh number

$\mathrm{Ra}_{\omega}: \quad$ Rotational Rayleigh number

Ta: $\quad$ Taylor number

$T: \quad$ Temperature (K)

$u, v: \quad$ Velocity components in the $x$ - and $y$-direction $(\mathrm{m} / \mathrm{s})$

$x, y \& X, Y$ : Space coordinates $(\mathrm{m}) \&$ dimensionless space coordinates.

Greek Symbols

$\beta$ : Thermal expansion coefficient $(1 / \mathrm{K})$

$\tau$ : Dimensionless time

$\tau_{p}$ : Dimensionless time for one rotation

$\Theta$ : Dimensionless temperature

$\Omega$ : Magnitude of angular rotation rate (rpm, $\mathrm{rad} / \mathrm{s})$

$\rho:$ Density $\left(\mathrm{kg} / \mathrm{m}^{3}\right)$

$\phi$ : Solid volume fraction

$\Psi$ : Dimensionless stream function

$\varphi$ : Angular position of enclosure (rad)

$\mu$ : Dynamic viscosity $\left(\mathrm{N} \mathrm{s} / \mathrm{m}^{2}\right)$.

\section{Subscript}

c: Cold

bf: Base fluid

$h$ : Hot

nf: Nanofluid

sp: Solid nanoparticles. 


\section{Conflict of Interests}

The authors declare there is no conflict of interests regarding the publication of this paper.

\section{References}

[1] S. U. S. Choi, "Enhancing thermal conductivity of fluids with nanoparticles," in Proceedings of the ASME Fluids Engineering Division, vol. 231, pp. 99-105, November 1995.

[2] W. Yu and H. Xie, "A review on nanofluids: preparation, stability mechanisms, and applications," Journal of Nanomaterials, vol. 2012, Article ID 435873, 17 pages, 2012.

[3] K. Buehler and H. Oertel, "Thermal cellular convection in rotating rectangular boxes," Journal of Fluid Mechanics, vol. 114, pp. 261-282, 1982.

[4] F. J. Hamady, J. R. Lloyd, K. T. Yang, and H. Q. Yang, "Study of natural convection in a rotating enclosure," Journal of Heat Transfer, vol. 116, no. 1, pp. 136-143, 1994.

[5] T. L. Lee and T. F. Lin, "Transient three-dimensional convection of air in a differentially heated rotating cubic cavity," International Journal of Heat and Mass Transfer, vol. 39, no. 6, pp. 12431255, 1996.

[6] Y. T. Ker and T. F. Lin, "Time-averaged and reverse transition in oscillatory air convection in a differentially heated rotating cubic cavity," International Journal of Heat and Mass Transfer, vol. 40, no. 14, pp. 3335-3349, 1997.

[7] Y. T. Ker and T. F. Lin, "A combined numerical and experimental study of air convection in a differentially heated rotating cubic cavity," International Journal of Heat and Mass Transfer, vol. 39, no. 15, pp. 3193-3210, 1996.

[8] M. F. Baig and A. Masood, "Natural convection in a twodimensional differentially heated square enclosure undergoing rotation," Numerical Heat Transfer A: Applications, vol. 40, no. 2, pp. 181-202, 2001.

[9] M. F. Baig and M. Zunaid, "Numerical simulation of liquid metals in differentially heated enclosure undergoing orthogonal rotation," International Journal of Heat and Mass Transfer, vol. 49, no. 19-20, pp. 3500-3513, 2006.

[10] L. F. Jin, K. W. Tou, and C. P. Tso, "Effects of rotation on natural convection cooling from three rows of heat sources in a rectangular cavity," International Journal of Heat and Mass Transfer, vol. 48, no. 19-20, pp. 3982-3994, 2005.

[11] C. P. Tso, L. F. Jin, and S. K. W. Tou, "Numerical segregation of the effects of body forces in a rotating, differentially heated enclosure," Numerical Heat Transfer A: Applications, vol. 51, no. 1, pp. 85-107, 2007.

[12] K. Khanafer, K. Vafai, and M. Lightstone, "Buoyancy-driven heat transfer enhancement in a two-dimensional enclosure utilizing nanofluids," International Journal of Heat and Mass Transfer, vol. 46, no. 19, pp. 3639-3653, 2003.

[13] H. F. Oztop, M. Mobedi, E. Abu-Nada, and I. Pop, "A heatline analysis of natural convection in a square inclined enclosure filled with a $\mathrm{CuO}$ nanofluid under nonuniform wall heating condition," International Journal of Heat and Mass Transfer, vol. 55, pp. 5076-5086, 2012.

[14] K. S. Hwang, J.-H. Lee, and S. P. Jang, "Buoyancy-driven heat transfer of water-based $\mathrm{Al}_{2} \mathrm{O}_{3}$ nanofluids in a rectangular cavity," International Journal of Heat and Mass Transfer, vol. 50, no. 19-20, pp. 4003-4010, 2007.
[15] A. K. Santra, S. Sen, and N. Chakraborty, "Study of heat transfer characteristics of copper-water nanofluid in a differentially heated square cavity with different viscosity models," Journal of Enhanced Heat Transfer, vol. 15, no. 4, pp. 273-287, 2008.

[16] E. Abu-Nada, "Rayleigh-Bénard convection in nanofluids: effect of temperature dependent properties," International Journal of Thermal Sciences, vol. 50, no. 9, pp. 1720-1730, 2011.

[17] C. J. Ho, M. W. Chen, and Z. W. Li, "Numerical simulation of natural convection of nanofluid in a square enclosure: effects due to uncertainties of viscosity and thermal conductivity," International Journal of Heat and Mass Transfer, vol. 51, no. 1718, pp. 4506-4516, 2008.

[18] C. Qi, Y. He, Y. Hu, J. Yang, F. Li, and Y. Ding, "Natural convection of $\mathrm{Cu}-$ Gallium nanofluid in enclosures," Journal of Heat Transfer, vol. 133, no. 12, Article ID 122504, 2011.

[19] Y. He, C. Qi, Y. Hu, B. Qin, F. Li, and Y. Ding, "Lattice Boltzmann simulation of alumina-water nanofluid in a square cavity," Nanoscale Research Letters, vol. 6, article 184, 2011.

[20] E. Büyük Öğüt, "Natural convection of water-based nanofluids in an inclined enclosure with a heat source," International Journal of Thermal Sciences, vol. 48, no. 11, pp. 2063-2073, 2009.

[21] H. C. Brinkman, "The viscosity of concentrated suspensions and solutions," The Journal of Chemical Physics, vol. 20, no. 4, pp. 571-581, 1952.

[22] F. H. Harlow and J. E. Welch, "Numerical calculation of time-dependent viscous incompressible flow of fluid with free surface," Physics of Fluids, vol. 8, no. 12, pp. 2182-2189, 1965.

[23] K. A. Hoffmann and S. T. Chiang, Computational Fluid Dynamics Volume I, Engineering Education System, Wichita, Kan, USA, 2000.

[24] D. Lin and W.-M. Yan, "Experimental study of unsteady thermal convection in heated rotating inclined cylinders," International Journal of Heat and Mass Transfer, vol. 43, no. 18, pp. 3359-3370, 2000. 


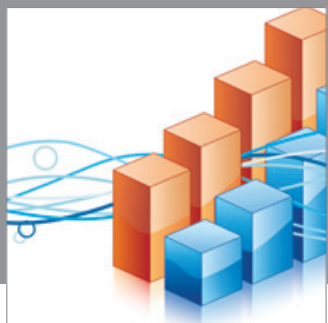

Advances in

Operations Research

mansans

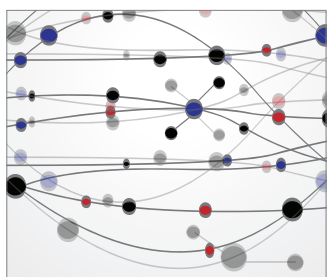

The Scientific World Journal
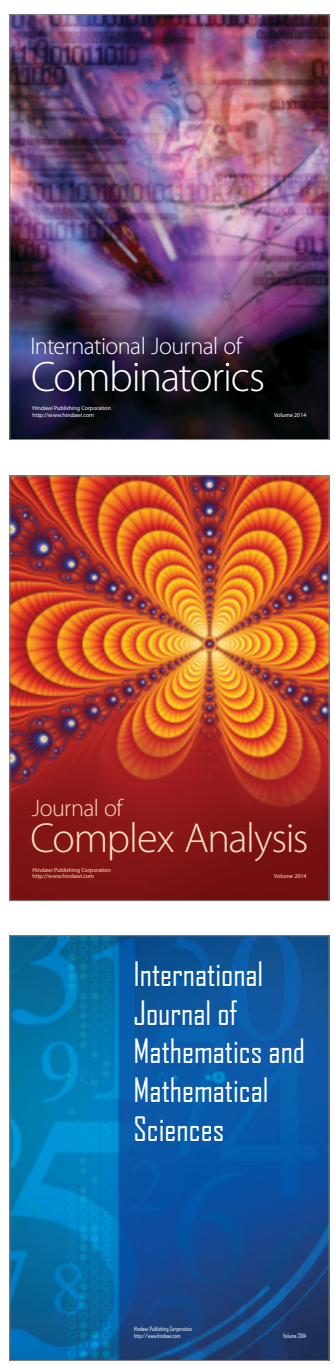
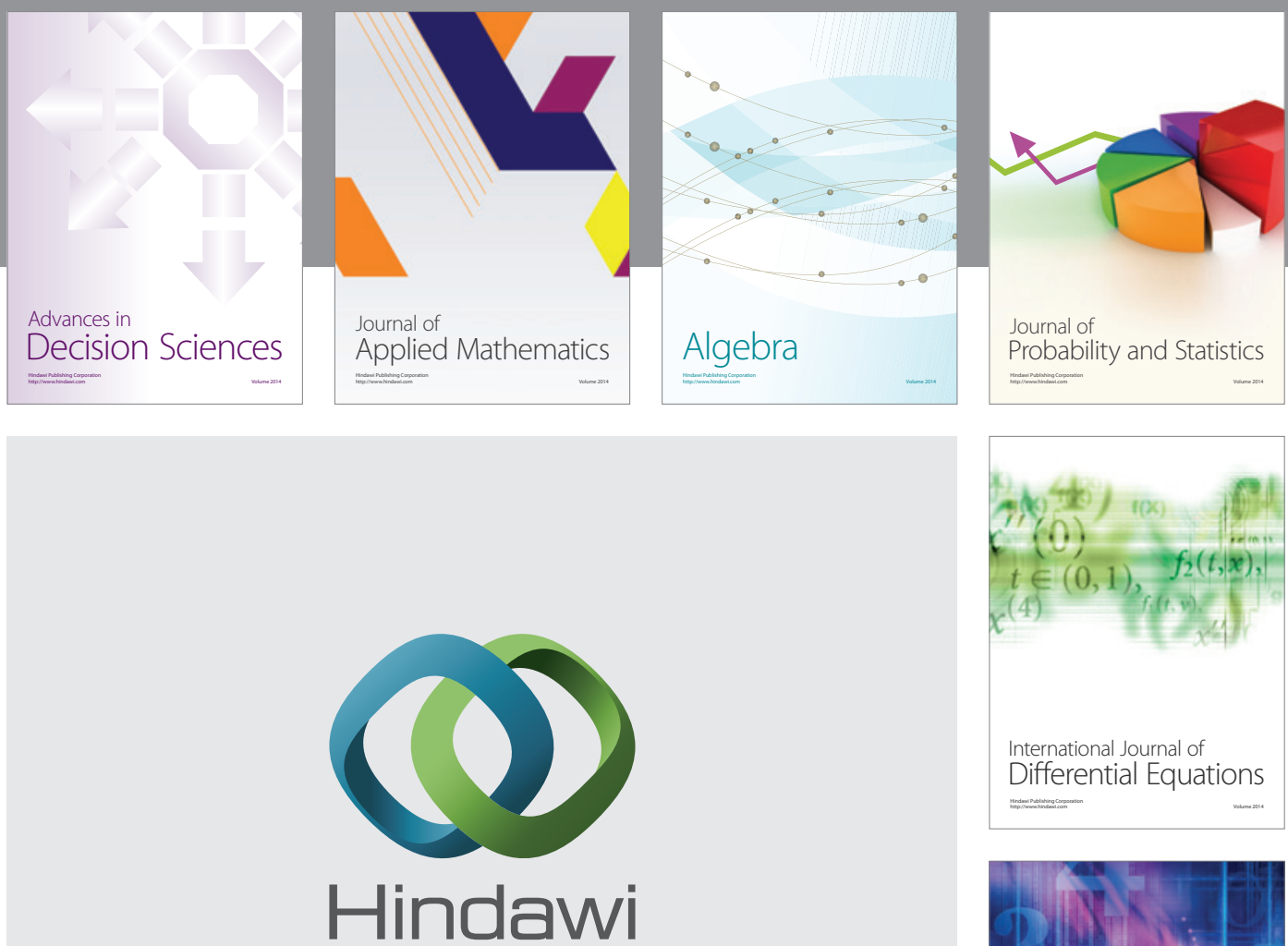

Submit your manuscripts at http://www.hindawi.com
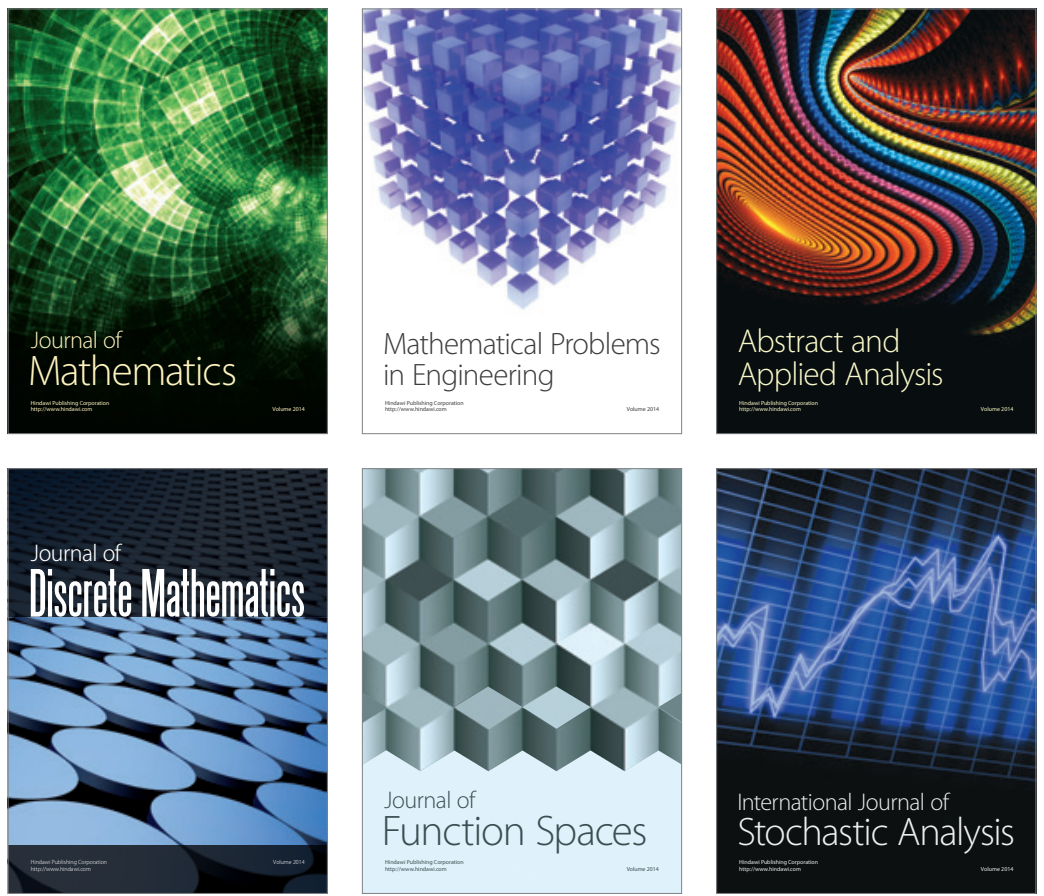

Journal of

Function Spaces

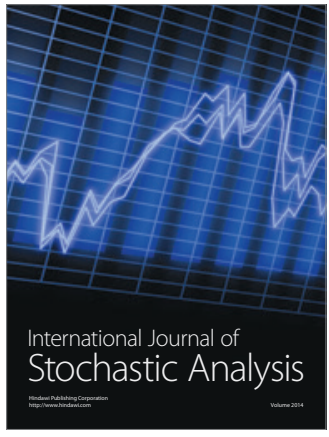

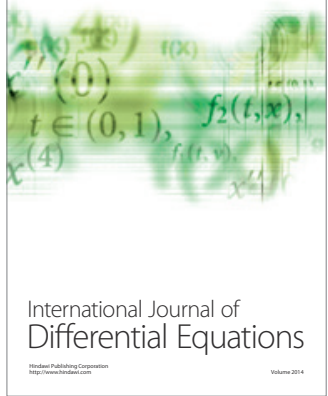
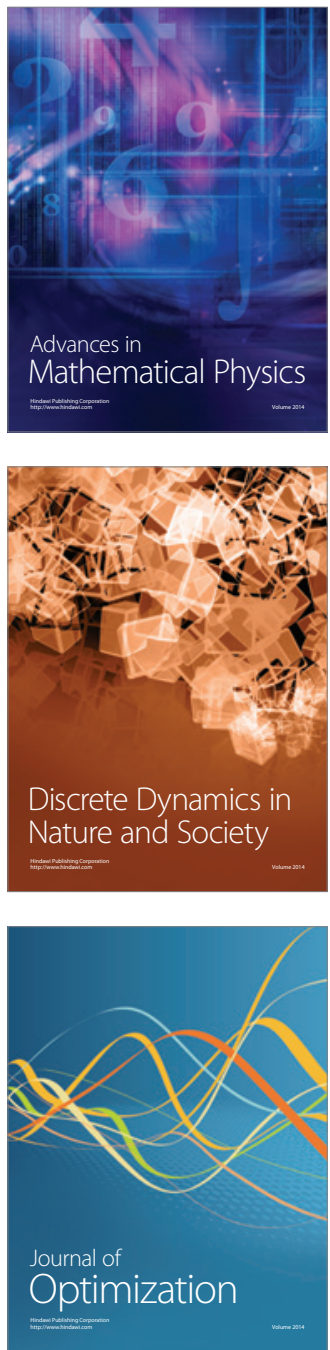